\title{
Reflection on the Cultivation of Art-Majored Talents of Broadcasting and Hosting in Colleges and Universities Based on the New Media Perspective
}

\author{
Peiyun $\mathrm{Shi}^{1, *}$
}

\author{
${ }^{1}$ Sichuan University of Culture and Arts, Mianyang, Sichuan, China \\ *Corresponding author.Email:97351048@qq.com
}

\begin{abstract}
The advent of the new media era has brought tremendous changes to the entire news media industry, among which more requirements have been put forward for broadcasting and hosting talents among working staff in media business. In this context, it's imperative to strengthen the training of broadcasting and hosting talents in colleges and universities. Starting from the perspective of new media, this article analyzes the current situation of the training of broadcasting and hosting talents in colleges and universities based on the goal of cultivating broadcasting and hosting talents, combines with the development needs of broadcasting and hosting talents in the new media era, and explores the teaching methods and innovative strategies to cultivate talents of colleges and universities who can closely integrate with social development.
\end{abstract}

Keywords: New media perspective, Broadcasting and hosting, Talent cultivation, Innovation.

\section{INTRODUCTION}

With the rapid development of the Internet, new media has had a huge impact on traditional media. New media has accelerated the integration of media, changed the way people use media, and adjusted the production process and propagation mode of information. At the same time, it puts more demands on working staff in media business. Broadcasting and hosting talents are a very important part of the media industry, and the demand for broadcasting and hosting talents is increasing. However, the current training level of broadcasting and hosting talents in colleges and universities is obviously lagging behind the specific needs of the media industry, resulting in a shortage of talents in the media industry. In view of the new media era has put forward higher requirements for the training of broadcasting and hosting talents in colleges and universities, this article discusses how to implement innovations and strategies for cultivating broadcasting and hosting talents in colleges and universities from the perspective of new media, and cultivating more broadcasting and hosting talents that meet the needs of new media development.

\section{REQUIREMENTS FOR BROADCASTING AND HOSTING TALENTS FROM THE PERSPECTIVE OF NEW MEDIA}

\subsection{The Strong Interactivity of Broadcasting and Hosting in the New Media Era}

In the rapid development of the Internet, the era of new media has arrived, and different network platforms are also growing, which to a certain extent, make the traditional broadcasting and hosting industry change a lot, and in terms of the form of news report, great changes have taken place. The rapid development of new media has drawn the distance between the host and the audience close, and the interaction between the audience and the host has increased. Specifically, in the new media platform, the broadcasting and hosting can conduct customized reports according to the audience's hobbies; compared with the report form of traditional media, the dissemination of information in the new media era has a stronger feedback effect. The information is transmitted to the audience, and the audience's feedback speed is faster. In the process of broadcasting and hosting work, the audience has 
more and more interaction with the host through new media, which narrows the distance between the host and the audience, and reflects the characteristics of discourse equality of the broadcasting and hosting work in the new media era. In the traditional form of broadcasting and hosting, the audience has less communication with the broadcasting and hosting personnel, while in the era of new media, the audience can even question the host through the platform. In the process, the host also needs to have strong on-site response ability.

With the rapid development of the Internet, new media platforms continue to emerge. At the same time, the scope of employment of broadcasting and hosting personnel in the new media era has gradually become wider. For example, they can use a wide range of live-broadcasting platforms and microblog platforms to carry out their work. The number of audiences is wider than that of traditional media, and the audience pay more attention to the host. While watching related programs, the audience also pays more attention to the interaction with the host, which is reflected in the audience's real-time comments, messages, and suggestions on the program. In the process of the interaction between the audience and the broadcasting and hosting personnel, on the one hand, the host is supervised, and on the other hand, higher requirements are put forward for the host's comprehensive ability. The host must have a strong ability to interact and guide, so as to ensure the professionalism of his own language and expression methods, and at the same time, to attach importance to the choice of language forms and the dissemination of information. This requirement is comprehensive, including requirements for the host's own abilities, professional ethics, and even the host's private life.

\subsection{The Diversification of Broadcasting and Hosting Styles in the New Media Era}

The advent of the new media era has made daily life more convenient, and it has also made working methods more convenient. All walks of life have carried out corresponding reforms and innovations in response to the arrival of new media to cope with the development of the new era. The broadcasting and hosting industry also needs to deal with the development of new media. Regarding broadcasting and hosting, the style of broadcasting and hosting needs diversified development. In the new media era, there is an increasing demand for broadcasting and hosting, such as dubbing of short videos, hosting on live-broadcasting platforms, and hosting on microblog platforms.
Among the CCTV news anchors, Zhu Guangquan is a broadcasting and hosting host with a variety of styles. In the eyes of the audience, the characteristics of the news anchors in the impression are serious. They often lack personalized features. According to research on news anchors, it's found that audience tend to have a preference for personalized news anchors. The CCTV news anchor Zhu Guangquan has a distinct personality and often presents news in a humorous way, such as broadcasting the news in rhyme, making the news more life-like and allowing the audience to feel the real existence of the anchor more truly. In this way, the distance between the audience and the host is shortened, and the program process is equivalent to a communication process. In this kind of broadcasting and hosting atmosphere, the audience becomes more receptive to the message that the host wants to spread. In addition, Zhu Guangquan once connected with Li Jiaqi during the CCTV live broadcast, which embodied his professionalism and personal characteristics, attracting more audiences, and making more audiences become fans of his programs.

The CCTV host Sa Beining and CCTV news anchors Kang Hui and Li Zimeng participated in the reality show "Hello, Life". Among them, two news broadcasters demonstrated their characteristics through the program. Compared with seeing them only on news channels before, this program allows the audience to have a clearer understanding of the status of the CCTV anchors in their lives. The audience also knows the strong comprehensive ability of the broadcasting and hosting personnel through the program, making it easier for the audience to accept the TV programs of the broadcasters, attracting more audiences and forming a good atmosphere. Another host, Sa Beining, further embodies the diversity of hosting styles. As the host of law programs, Sa Beining is serious and dignified; as the host of knowledge programs, he is knowledgeable; as the host of entertainment programs, he is humorous and lively, reflecting the diversity of his style as a host. In the face of the new media era, in order to better promote the development of news dissemination, broadcasting and hosting personnel need to improve their professional capabilities and disseminate information with diversified hosting styles.

\subsection{The Professionalization of Broadcasting and Hosting in the New Media Era}

In the context of new media, broadcasting and hosting personnel need to have a stronger sense of news, because in an environment with fast 
information dissemination and much information content, the audience have higher requirements for receiving information. The broadcasting and hosting personnel should have strong news sensitivity and news awareness in order to always maintain their strong competitiveness and adapt to the development of the new media era.

In the context of new media, higher requirements are put forward for the professional ability of broadcasting and hosting personnel. In the process of information dissemination, the broadcasting and hosting personnel have a strong interaction with the audience, which puts up with high requirements on the broadcasting and hosting personnel's on-site control ability and on-site expression ability. The audience radiated by the audience in the current program is becoming wider and wider. While the broadcasting and hosting personnel have strong professional capabilities, they also need to master the background knowledge related to the program. Taking financial programs as an example, the host must not only be able to use his own professional knowledge to control the program, but also need to conduct financial professional discussions with the guests, and have comprehensive capabilities to effectively control the program and gain the recognition of the audience.

\section{CURRENT SITUATION OF CULTIVATION OF BROADCASTING AND HOSTING TALENTS IN COLLEGES AND UNIVERSITIES FROM THE PERSPECTIVE OF NEW MEDIA}

\subsection{Traditional Characteristics of Training Goals}

At present, Chinese colleges and universities still have relatively traditional goals in training talents from the broadcasting and hosting major. Generally, they set up courses and implement corresponding talent training goals around radio and television media. The main talents to be cultivated are applied talents who can engage in related work such as broadcasting and hosting or news dissemination in traditional radio and television and other media units. In the context of new media, this training goal is relatively narrow, which often leads to weak adaptability of broadcasting and hosting talents. In the current requirements of training goals, in terms of the teaching of broadcasting and hosting majors in colleges and universities, the teaching of radio and television broadcasting courses is very important. In the teaching process, the teaching of basic skills is generally emphasized, including several aspects, such as students' Putonghua pronunciation, broadcasting phonation, language expression, etc. It is relatively lacking in the cultivation of students' news literacy, especially in the stage of rapid development of new media, new media curriculum should be effectively targeted and set up. Although some colleges and universities offer courses related to new media, they change the shell rather than the content, and they still adopt traditional curriculum training methods. In the face of the social trend of the rapid development of new media, the current broadcasting and hosting majors need to adjust the curriculum setting and broaden the teaching and training goals.

\subsection{The Unicity of Teaching Mode}

At present, most of the majors of broadcasting and hosting in colleges and universities adopt the mode of "enlarged class + smaller class", which still needs to be continuously improved in the specific practical teaching process. In the process of theoretical teaching in enlarged class, many teachers often teach completely according to the content of the textbook, and more often teach and instill theories based on textbooks and their own experience, ignoring the syncretic teaching in combination with current actual cases and resulting in the lack of students' interest in learning. The form of the smaller class mainly includes checking and making up for the deficiencies of students and the teachers' demonstration teaching. From the perspective of students, this type of teaching model can take care of every student, and to a certain extent can enhance students' enthusiasm for learning. But in general, as the only information disseminator in teaching, it's difficult for teachers to guide and inspire students in multiple directions, which easily leads to the cultivation of talents of the same type; this can't meet the diverse needs of the news and communication industry for broadcasting and hosting talents in the context of new media.

\subsection{The Lack of Practical Teaching}

The broadcasting and hosting major is a very practical art major. The quality of practical teaching directly affects the training of talents for broadcasting and hosting. Nationwide, many colleges and universities have opened broadcasting and hosting majors, and the overall number of students is showing an increasing trend. However, the hardware facilities of many colleges and universities can't meet the requirements of students' practical training 
creation, resulting in fewer opportunities for students to practice. Some colleges and universities have built training rooms, but they can't meet the actual requirements of the media. Some colleges and universities only carry out practical teaching in the campus, lacking of connecting with the media and resulting in the disconnection between the talent training and society. At present, there are more and more colleges and universities offering broadcasting and hosting majors, but the overall quality of practical teaching is uneven. Some colleges and universities have been able to achieve effective docking with social media, and some colleges are still in a state where the simulation teaching is the mainstay, which has affected the cultivation of students' practical ability to a certain extent.

\subsection{The Shortage of Teachers}

Some colleges and universities have insufficient teachers. Broadcasting and hosting teachers need to be well-trained and rich in practical experience, but the actual situation often has obvious shortcomings. A large proportion of teachers graduate directly from colleges and universities, and lack teaching experience and media practice. These teachers themselves are still in the process of learning, but they are responsible for the main courses, which affects the quality of teaching to a certain extent. In addition, some older teachers lack knowledge of new media and still use traditional media to deal with teaching, and the teaching process is more procedural. Some teachers are first-line presenters and announcers in the industry, but the teaching time of such teachers is often difficult to guarantee, and the lack of teaching experience affects the communication between teaching and learning, which affects the quality of teaching.

\section{INNOVATIONS AND STRATEGIES FOR THE TRAINING OF BROADCASTING AND HOSTING TALENTS IN COLLEGES AND UNIVERSITIES FROM THE PERSPECTIVE OF NEW MEDIA}

\subsection{Cultivating All-round Broadcasting and Hosting Talents}

In the context of new media, the rapid development of the media industry has gradually increased the demand for professional talents in broadcasting and hosting, which has brought more opportunities for broadcasting and hosting majors in colleges and universities. The integration of media and the development of the Internet have expanded the employment scope of broadcasting and hosting personnel to a certain extent, covering multiple fields such as online media, live-broadcasting platforms, short videos, and culture propaganda. This also puts forward more requirements for colleges and universities to train professional talents for broadcasting and hosting. In order to cope with the development of new media, the broadcasting and hosting majors of colleges and universities must challenge the training goals and talent training models originally formulated for traditional broadcast and television media, closely follow the development trend of new media, carry out in-depth research on the talent market of the media industry of new media, and effectively cultivate new media professionals with "one specialty and multiple skills"; in terms of training models, efforts should be always made to create a student-centered and innovative teaching environment for all-round development, establish the concept that teaching serves learning, pay attention to cultivating students' media literacy and innovation awareness, and cultivate compound and applied talents who can be employed upon graduation.

In the era of new media, the requirements for professional talents of broadcasting and hosting have turned to "one specialty and multiple skills". At present, the training of broadcasting and hosting personnel in colleges and universities is still positioned on the standards of traditional radio station hosts, and the overall teaching plan is lagging behind; in terms of teaching mode, it still attaches importance to classroom indoctrination rather than practical activity training, lacking the mobilization of thinking and integration with the new media environment, and failing to effectively mobilize students' innovation ability and learning enthusiasm.

It's necessary to focus on cultivating the professionalism of students and the social responsibility consciousness of media professionals. The broadcasting and hosting personnel are firstly journalists, and the characteristic of journalism is the fundamental attribute of the broadcasting and hosting. But with the generalization of the media, the aura of media professionals has faded compared to before. Regaining professional self-confidence and inheriting professionalism are especially necessary for training students of broadcasting and hosting. The students majoring in broadcasting and hosting have better own conditions and are cared relatively more by their families. They tend to neglect their studies and don't want to endure hardship. The teaching of broadcasting and hosting majors needs to pay 
attention to the daily teaching process, which should strengthen the training of students to improve their professionalism, pay attention to improving students' awareness of social responsibility, let students participate in social practice activities, improve their professional abilities in social practice activities, and make them pay attention to social problems, experience the lives of the common people and perceive the fickleness of human nature, so as to enable them to be in awe of the major and possess a strong sense of professionalism and social responsibility.

It's needed to pay attention to cultivating students' basic professional skills and the cultivation of students' cultural deposits. Students' mastering the basic skills can affect the life of the broadcasting and hosting personnel. They have solid basic skills and can quickly and effectively improve their professional capabilities and become more outstanding professionals. Against the background of new media, people's needs are diversified, and the improvement of people's knowledge level makes TV programs show a trend of professionalism. In view of the professionalization of programs and the diversification of audiences, broadcasting and hosting personnel need to have stronger comprehensive capabilities. In addition to strong professional capabilities, they need to have strong cultural deposits and comprehensive capabilities. The host Dong Qing can be taken as an example, and a poem program she hosts is very successful. The guests, contestants and host in this program are very familiar with ancient poetry, especially Dong Qing, as the host, can control the site well, which has a close relationship with Dong Qing's own cultural deposits. The host Dong Qing has solid cultural deposits and is quite capable of hosting and controlling this program. Moreover, the current broadcasting and hosting personnel not only need to possess clear articulation and a mellow and full tune and a lovely face, but also often need to participate in the process of program content collection and compilation. If they lack good cultural deposits, they can't grasp the focus, so it's imperative to improve the cultural quality of broadcasting and hosting personnel.

\subsection{Effectively Combining with New Media Platforms}

In the context of new media, the professional construction of broadcasting and hosting majors in colleges and universities needs to be combined with new media and apply the new media to the curriculum. It's necessary to make full use of the teaching platforms of the Internet and other new media to build a comprehensive teaching system in the school. Efforts should be made to change the previous single and relatively closed classroom teaching mode, effectively highlighting the main body status of students in the process of broadcasting and hosting teaching. Students should be fully exposed to new media, naturally integrate into new media, and be provided with an open network platform. For example, by opening online radio stations and online programs, students can practice creation through this type of new media platforms, and have a clearer understanding of the precise positioning of broadcasting and hosting in the context of new media. In addition, it's necessary to carry out diversified information interaction through practical creation, such as cooperation between different majors, cooperation between different schools, cooperation between schools and social media, to provide more practical platforms for students majoring in broadcasting and hosting.

\subsection{Strengthening the Diversity of Practical Teaching}

In the era of new media, colleges and universities are gradually strengthening the training of professional talents in broadcasting and hosting, and strengthening practical teaching is the top priority among them. It's necessary to reflect the student's dominant position in practical teaching. Practical teaching should be carried out in three ways: simulation classroom, competition to promote teaching, and media integration.

The first is to implement practical teaching in a way of simulation classroom. In the case of teaching students specific practical professional knowledge, teachers need to adopt the project teaching method to allow students to actively participate. In the teaching process of the project, teachers simulate a specific case, and then give a specific program topic selection, allowing students to actively participate in the creation. Students select specific program topics, form a project team, and complete the production of the program, including the pre-planning of the program, on-site interviews, copywriting, hosting, and post-production, which should be completed by the project team alone. In the simulation classroom, the teacher assumes the role of guidance, and the students are the main practice subjects, playing their main role in the practice process.

The second is to use competition to promote teaching to carry out practical teaching. The students of broadcasting and hosting need to show themselves 
through a large number of practical platforms. The combination of practical teaching and various competitions provides students with a stage to show themselves. For example, the host contest can be taken as an example. In the host contest, different topics are set up in the contest, and the participating students come from different schools, which provide them with better practice opportunities. Students need to use their professional knowledge in the competition and teachers play a guiding role in the competition. The goal of teachers and students to complete the competition project through joint practice breaks the traditional practice teaching method, turning passive practice into active participation, emphasizing active learning, competition and cooperation in the process of practice, and giving full play to the teacher's leadership role and the main body role of students.

In the practical teaching mode of "competition to promote teaching", it fully embodies the promotion of teaching and the improvement of students' practical creative ability by participating in competitions. The key is the design of "competition to promote teaching", constructing a series of typical operable "competitions to promote teaching", so that students can master knowledge, skills and methods in completing "competitions to promote teaching". It's necessary to introduce a competition mechanism into competitions and projects, and to lead the students to rapidly improve their independent practice level.

The third is the integration with the media, that is, the cooperation between the school and the media unit. First of all, it can be cooperation with campus media, such as business cooperation with campus TV stations or new media centers to produce fixed episodes of programs including the complete production of the entire program and interdisciplinary fusion creation with other professional students. This measure allows students to truly experience the actual combat status. The production of the entire program is implemented strictly in accordance with the standardized process. Students can quickly become quasi-media professionals, laying a solid foundation for them to become media professionals. Second, the media outside the school can also be cooperated with.

\section{CONCLUSION}

In response to the higher requirements put forward by the development of new media for broadcasting and hosting talents, colleges and universities must clarify the training goals of the professional talents in the process of training broadcasting and hosting professionals, highlight the teaching mode of teachers' guidance and students as the main body in the teaching process, pay attention to the diversified development of styles of students majoring in broadcasting and hosting, pay attention to the cultivation of students' professional ability, pay attention to the cultivation of students' professional ethics and the cultivation of cultural deposits, improve students' comprehensive ability, make full use of the new media platform to build a practical teaching system, gradually improve the quality of practical teaching, and cultivate more all-round broadcasting and hosting professionals for the media industry.

\section{AUTHORS' CONTRIBUTIONS}

This paper is independently completed by Peiyun Shi.

\section{REFERENCES}

[1] Li Yilian. Research on the Art Teaching of Broadcasting and Hosting in Colleges and Universities Under the New Media Environment [J]. Dangdai Jiaoyan Luncong, 2016 (11): 1516. (in Chinese)

[2] Ma Xiaohong. Innovation in the Art of Broadcasting and Hosting in the New Era [J]. Research on Transmission Competence, 2019,3(20):136,150. (in Chinese)

[3] Liang Chao. Reflections on the Broadcasting and Hosting Majors in the Context of New Media - On the Style Innovation of Broadcasting Hosts [J]. New Media Research, 2017 (3). (in Chinese)

[4] Zeng Fanyi. The Development of Radio and Television Broadcasting and Hosting Work Under the New Media Environment [J]. New Business Weekly, 2017 (19). (in Chinese)

[5] Liu Yilin. Research on Innovative Practice Teaching of Broadcasting and Hosting Major in Universities [J]. Audiovisual, 2018(12). (in Chinese)

[6] Cheng Yaxin. Training Mode of Professional Talents of Broadcasting and Hosting Art in Colleges and Universities in the Era of New Media Innovative Research [J]. Contemporary Educational Practice and Teaching Research, 2016(3). (in Chinese) 